\title{
THE REFLECTIVE CRACKING IN FLEXIBLE PAVEMENTS
}

Jorge Pais, Associate Professor, University of Minho, Guimarães, Portugal, e-mail: jpais@ civil.uminho.pt

\begin{abstract}
Reflective cracking is a major concern for engineers facing the problem of road maintenance and rehabilitation. The problem appears due to the presence of cracks in the old pavement layers that propagate into the pavement overlay layer when traffic load passes over the cracks and due to the temperature variation. The stress concentration in the overlay just above the existing cracks is responsible for the appearance and crack propagation throughout the overlay. The analysis of the reflective cracking phenomenon is usually made by numerical modeling simulating the presence of cracks in the existing pavement and the stress concentration in the crack tip is assessed to predict either the cracking propagation rate or the expected fatigue life of the overlay. Numerical modeling to study reflective cracking is made by simulating one crack in the existing pavement and the loading is usually applied considering the shear mode of crack opening. Sometimes the simulation considers the mode I of crack opening, mainly when temperature effects are predominant.
\end{abstract}

Keywords: Reflective cracking, Numerical modeling, Road pavements

\section{REFLECTIVE CRACKING}

Overlays are the most commonly used method for rehabilitating cracked pavements. However, they often do not perform as expected because of existing cracks that propagate through the newly constructed overlay within a short period of time [1]. This problem is called "reflective cracking" and is well identified when an overlay shows a crack pattern identical to that existing in the old pavement. When an overlay is placed on a cracked pavement, the cracks in the old pavement surface will propagate through the overlay and will appear in the surface.

Reflective cracking is caused by thermal contraction, by repeated traffic loads, or by a combination of these mechanisms. In addition, the temperature dependent stiffness of the materials and flaws in the overlay (i.e. built-in cracks during construction) as reported by Halim et al [2] can have an important effect. 
ROMANIAN JOURNAL

\section{OF TRANSPORT INFRASTRUCTURE}

Jorge Pais,

The reflective cracking in flexible pavements

Existing overlay design methods do not take into account reflective cracking. The only form of cracking typically mechanically modeled is flexural fatigue, which only captures the following phenomena:

- Tensile strain at the bottom of the overlay - especially for thicker overlays when the neutral zone is above the bottom of the new overlay;

- Tensile strain at the bottom of the existing asphalt concrete especially for relatively intact (uncracked) pavements;

- Compressive stresses or strains at the top of the unbound materials when the failure mechanism is not fatigue cracking.

However, to minimize or delay crack propagation, some other experience based techniques are used which include the increase of overlay thickness, modification of asphalt properties or a stress-absorbing interlayer placed between the existing pavement and the overlay layer.

Even so, the existing cracks propagate up to the new pavement surface producing a too early failure of the entire pavement with high costs for the Highways Agencies and for the road users. Thus, the development of an overlay design method, which includes a criterion for reflective cracking, is of great importance for road maintenance.

A design method to take into account the reflective cracking must consider the discontinuity produced by the cracks on the existing pavement. This cracking condition can only be modeled using a special numerical technique such as finite element analysis which is associated with fracture mechanics concepts.

\section{CRACK ACTIVITY}

Load associated reflective cracking is governed simultaneously by horizontal opening and/or closing and a vertical shearing at the crack zone. The simulation of this process must consider the simultaneity of these two modes of opening in the analysis of this problem. These movements can be measured by transducers placed on both side of the pavement cracks and one of the most used methods to assess these movements is the Crack Activity Meter (CAM) which is composed of two LVDT (Linear Variable Differential Transformers), one placed vertically and the other placed horizontally allowing the measurement of both differential movements. Figure 1 shows a schematic representation of the CAM placed over the crack. 
ROMANIAN JOURNAL

\section{OF TRANSPORT INFRASTRUCTURE}

Jorge Pais,

The reflective cracking in flexible pavements

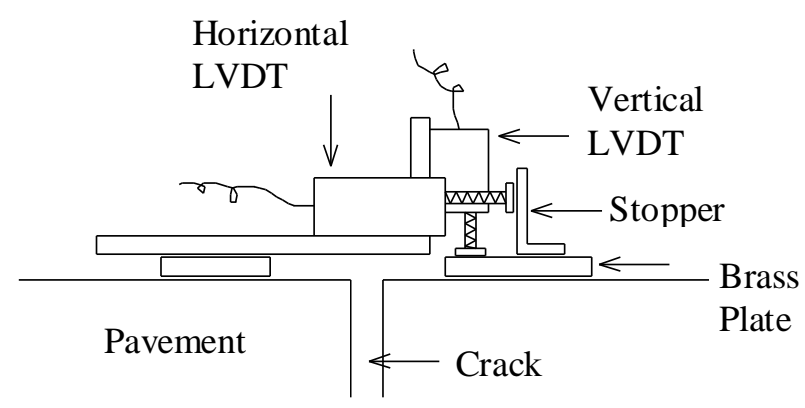

Figure 1. Crack Activity Meter

The work developed by Pais [3] reports the evaluation of the crack activity before overlay on 16 cracked cross sections of flexible pavements, with 500m long, in the Portuguese road network. 13 transversal cracks and 11 longitudinal cracks were analyzed. The typical crack activity for a longitudinal crack is shown in Figure 2 while Figure 3 shows the typical crack activity for transversal cracks. Horizontal positive values represent opening of the crack while negative values represent crack closing.

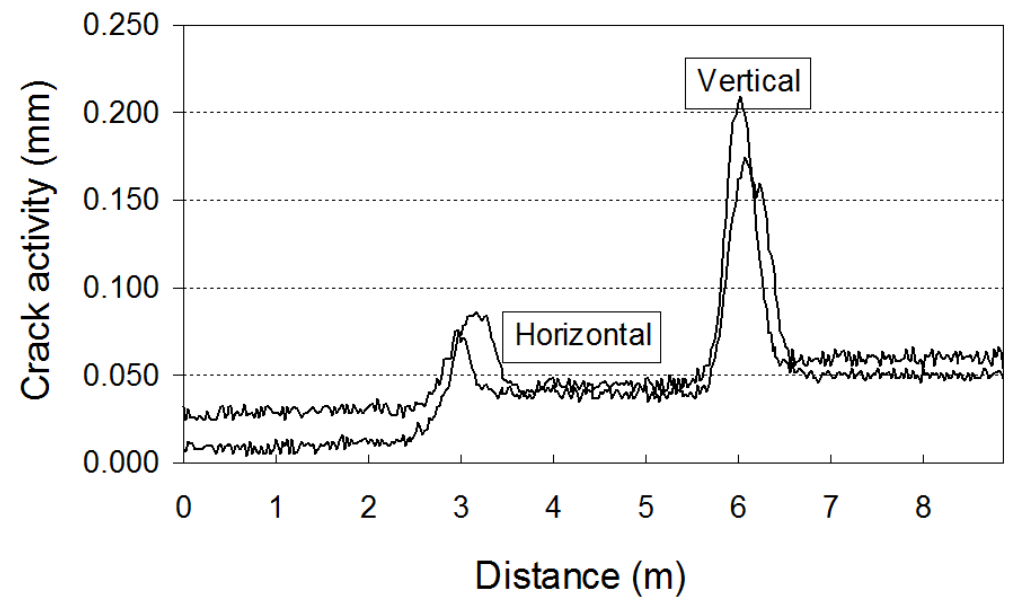

Figure 2. Crack movements of the longitudinal crack before pavement overlay 
ROMANIAN JOURNAL

\section{OF TRANSPORT INFRASTRUCTURE}

Jorge Pais,

The reflective cracking in flexible pavements

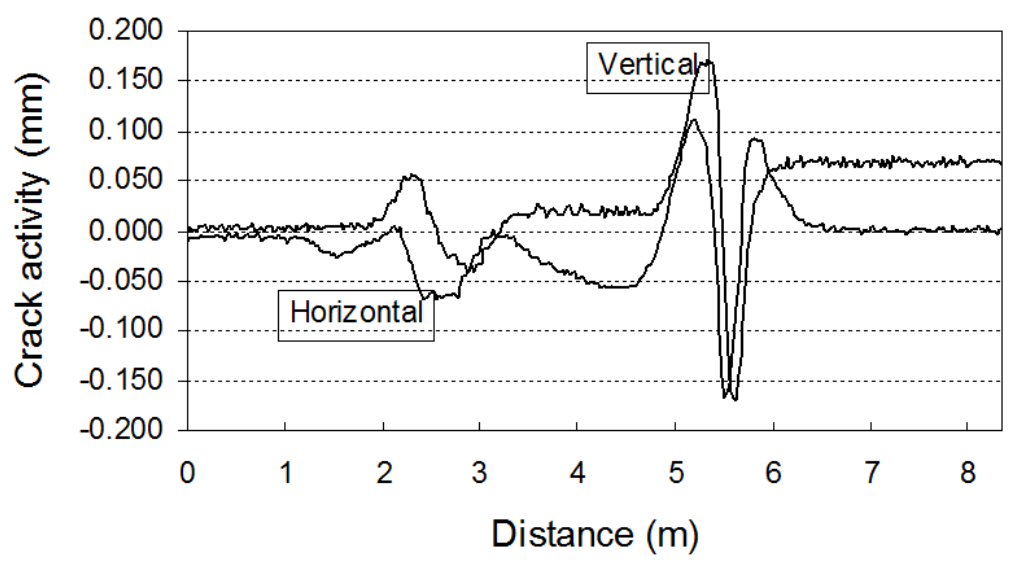

Figure 3. Crack movements of the transversal crack before pavement overlay

3D FEM solid mesh presented in Figures 4 represents a model for a cracked pavement with for a linear elastic analysis to predict the crack activity of the pavement before overlay. The pavement has 3 layers, a bituminous cracked layer, a granular layer and a subgrade layer. A longitudinal crack is also represented in a model with $4.70 \mathrm{~m} * 2.4 \mathrm{~m}$ (due to symmetrical pavement configuration) * pavement thickness. If the pavement has more than 3 layers, a usual situation in flexible pavements, layers of identical materials must be included in one layer.

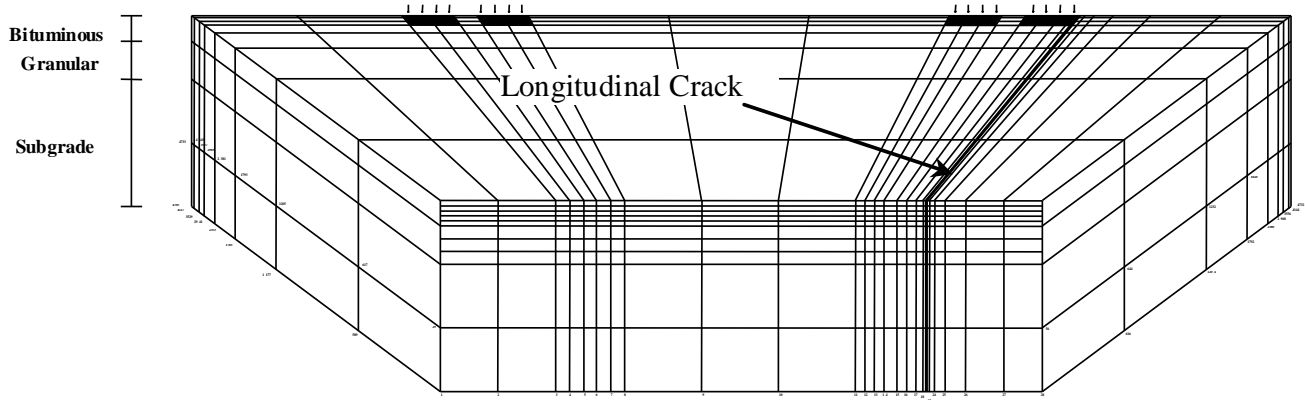

Figure 4. Finite element model to simulate the crack activity before overlay

It has been demonstrated by Pais [3] that the most important component of the crack activity is the relative vertical displacement. This is because after an overlay the horizontal displacements are reduced to extremely small values due to the strength of the asphalt layers. Because it is difficult to measure stresses in cracked pavements or overlays and it is relatively simple to measure crack activity, a model was developed to evaluate to which extent the same basic 
ROMANIAN JOURNAL

OF TRANSPORT INFRASTRUCTURE

principles and models being developed for the determination of the stresses in overlays could predict the vertical crack activity.

Using the 3D finite element model, the vertical crack activity before overlay was calculated to fit in a statistical model and the Equation [1] was obtained.

$$
A c t=a \cdot \log (\text { Tbet })+b \cdot \log (\text { Tgra })+c \cdot \log (\text { Mbet })+d \cdot \log (\text { Mgra })+e \cdot \log (\text { Msub })+f
$$

where: Act = vertical crack activity before overlay;

Tbet $=$ bituminous cracked layer thickness;

Tgra $=$ granular layer thickness;

Mbet $=$ bituminous cracked layer modulus;

Mgra = granular layer modulus;

Msub = subgrade modulus;

$\mathrm{a}, \mathrm{b}, \mathrm{c}, \mathrm{d}, \mathrm{e}, \mathrm{f}=$ statistical coefficients given by Table 1 .

Table 1. Coefficients for the model to predict the vertical crack activity before overlay

\begin{tabular}{|l|c|c|c|c|c|c|}
\hline Coefficient & $\mathrm{a}$ & $\mathrm{b}$ & $\mathrm{c}$ & $\mathrm{d}$ & $\mathrm{e}$ & $\mathrm{f}$ \\
\hline Value & 11.773 & -21.388 & -52.893 & -94.619 & -16.418 & 1181.66 \\
\hline
\end{tabular}

A comparison between the FEM calculated and the statistical estimated vertical crack activity before overlay is shown in Figure 5 where a good correlation can be observed.

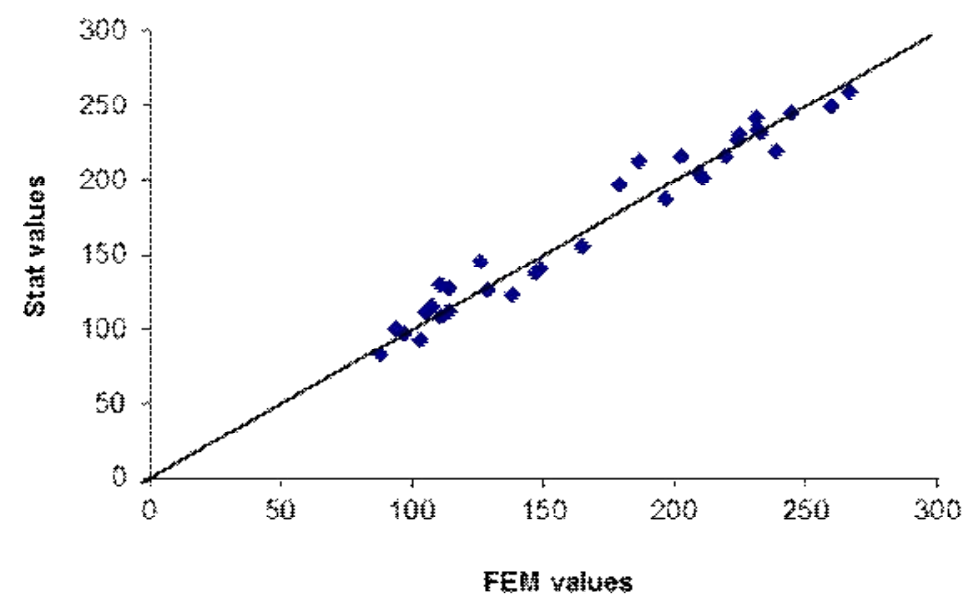

Figure 5. Comparison between FEM and Statistical vertical crack activity before overlay 
The validation of this 3D finite element model was made by comparing the crack activity before overlay measured in trial sections and the values given by the statistical model developed above. This comparison is presented in Figure 6 and it can be concluded that the finite element model simulates well a cracked pavement.

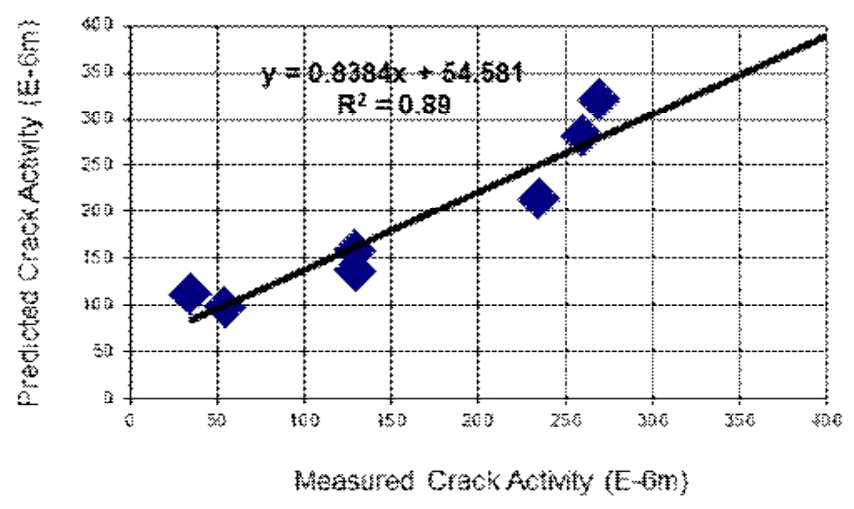

Figure 6. Comparison between measured and FEM predicted vertical crack activity before overlay

The small differences observed in this comparison, mainly due to low levels of crack activity, where the finite element model gives larger values than the measured, could possibly be due to the evaluation of pavement layer modulus in cracked zones where the pavement shows a non-constant linear behavior.

However, the design of a pavement overlay needs the knowledge of the state of stress/strain of the pavement after overlay. This state can be evaluated by modeling the cracked pavement with an overlay layer. If the state of stress/strain is considered by the crack activity, the movements after overlay must be assessed. This can be done using a 3D finite element model as shown in Figure 7. This model has 4 layers, an overlay layer, a bituminous cracked layer, a granular layer and a subgrade layer. 
ROMANIAN JOURNAL

\section{OF TRANSPORT INFRASTRUCTURE}

Jorge Pais,

The reflective cracking in flexible pavements

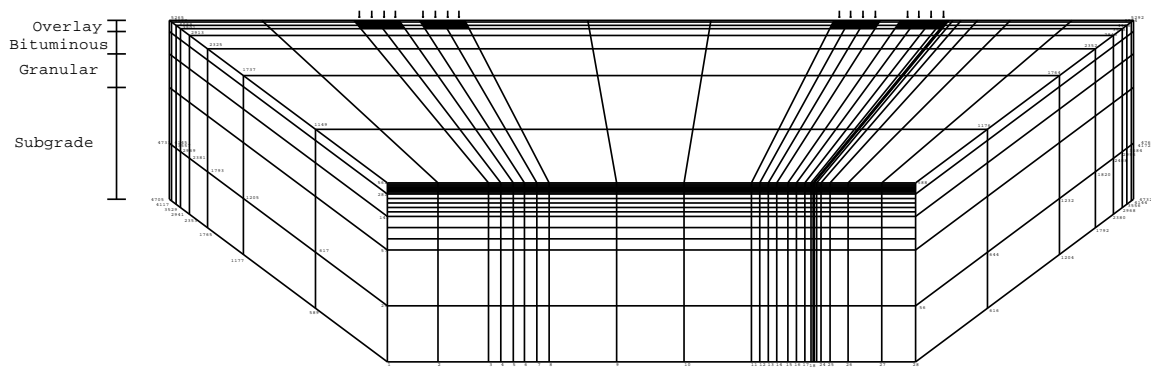

Figure 7. Finite element model representing the pavement overlay

Using the 3D finite element model, the vertical crack activity after overlay (VCAAO) was calculated to fit in a statistical model given by Equation 2.

VCAAO $\left(m .10^{-6}\right)=a *[\text { Overlay thickness }(m)]^{b}$

where:

$$
\begin{aligned}
& a=\prod_{i=1}^{6}\left[a_{1 i} * \ln \left(X_{i}\right)+a_{2 i}\right] \\
& b=\prod_{i=1}^{6}\left[b_{1 i} * \ln \left(X_{i}\right)+b_{2 i}\right]
\end{aligned}
$$

aij and bij coefficients are given by the Table 2 .

Table 2. Statistical coefficients for vertical crack activity after overlay model

\begin{tabular}{|c|l|l|l|l|l|}
\hline $\mathrm{i}$ & \multicolumn{1}{|c|}{ Xi } & \multicolumn{1}{c|}{$\mathrm{a}_{1 \mathrm{i}}$} & \multicolumn{1}{c|}{$\mathrm{a}_{2 \mathrm{i}}$} & \multicolumn{1}{c|}{$\mathrm{b}_{1 \mathrm{i}}$} & \multicolumn{1}{c|}{$\mathrm{b}_{2 \mathrm{i}}$} \\
\hline 1 & Cracked thickness (m) & $-1.190 \mathrm{E}-01$ & $-1.286 \mathrm{E}+00$ & $6.065 \mathrm{E}-02$ & $-8.820 \mathrm{E}-01$ \\
\hline 2 & Granular thickness (m) & $4.940 \mathrm{E}-01$ & $-3.279 \mathrm{E}+00$ & $4.751 \mathrm{E}-03$ & $2.967 \mathrm{E}-01$ \\
\hline 3 & Overlay modulus (MPa) & $-2.885 \mathrm{E}-01$ & $2.945 \mathrm{E}+00$ & $-8.227 \mathrm{E}-03$ & $1.457 \mathrm{E}+00$ \\
\hline 4 & Cracked modulus (MPa) & $1.734 \mathrm{E}-01$ & $-6.342 \mathrm{E}-01$ & $-1.826 \mathrm{E}-01$ & $3.036 \mathrm{E}+00$ \\
\hline 5 & Granular modulus (MPa) & $-9.188 \mathrm{E}-03$ & $6.512 \mathrm{E}-01$ & $-1.051 \mathrm{E}-01$ & $1.465 \mathrm{E}+00$ \\
\hline 6 & Subgrade modulus (MPa) & $-5.246 \mathrm{E}-01$ & $4.856 \mathrm{E}+00$ & $3.770 \mathrm{E}-02$ & $9.037 \mathrm{E}-01$ \\
\hline
\end{tabular}

The crack activity after overlay can be used to evaluate the reflective cracking fatigue life of the overlay by applying those movements to the asphalt mixture simulating the pavement overlay. Sousa et al [4] developed a Reflective Cracking Device (RCD) represented in Figure 8 which fit a cylindrical or rectangular specimen to be subject to vertical and horizontal movements representing the crack activity after overlay. 
ROMANIAN JOURNAL

\section{OF TRANSPORT INFRASTRUCTURE}

Jorge Pais,

The reflective cracking in flexible pavements

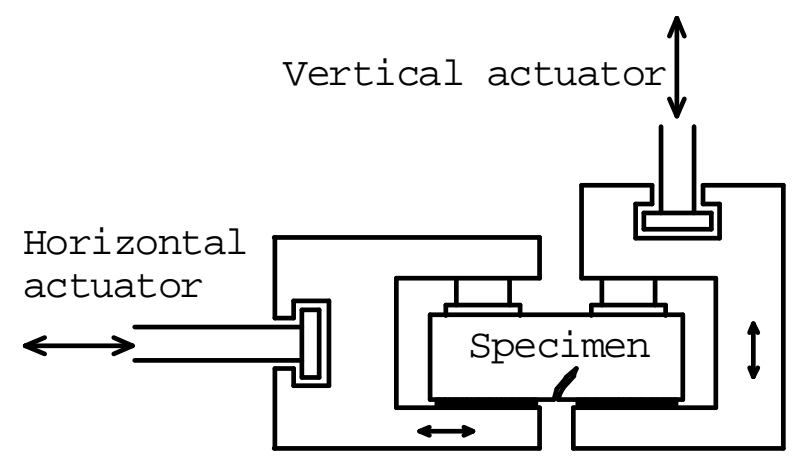

Figure 8. Schematic representation of the Reflective Cracking Device

The RCD represents the crack zone of the pavement overlay (Figure 9) that is subjected to the horizontal and vertical movements which leads to the cracking propagation from the old pavement to the new pavement layers.

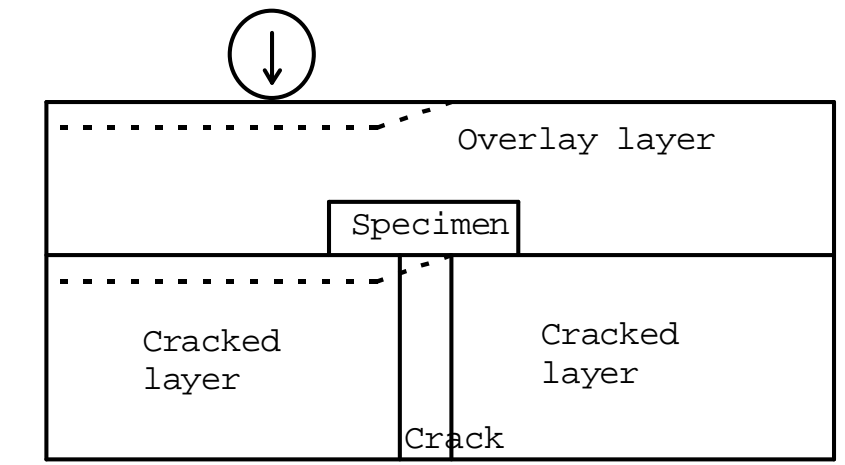

Figure 9. Schematic representation of the crack zone

To evaluate reflection cracking through overlays, Sousa et al [5] suggested that, an equivalent stiffness in the crack zone could be used to define the fatigue life for this problem. This equivalent stiffness is defined as the average stiffness in specimen volume above the crack and is defined as follows:

$$
S=\frac{F / L . H}{\delta / w}
$$

where $\mathrm{S}=$ equivalent stiffness in crack zone;

$\mathrm{F}=$ measured force;

$\delta=$ applied displacement;

$\mathrm{L}=$ crack length (i.e. specimen length);

$\mathrm{H}=$ specimen height;

$\mathrm{w}=$ crack width. 
ROMANIAN JOURNAL

The AASHTO TP8-94 standard test defines the fatigue life for flexural beam specimens when the specimen stiffness is reduced to $50 \%$ of the initial stiffness. For this study, the fatigue life can be defined as the number of load cycles to reach $50 \%$ of the initial equivalent stiffness in crack zone.

A reflective cracking fatigue model can be established using a linear regression between logarithm of fatigue life, $\log \mathrm{N}$, and the logarithm of displacement, $\log \Delta$, defined as follows:

$$
N=a\left(\frac{1}{\Delta}\right)^{b}
$$

where $\mathrm{N}=$ fatigue life;

$\Delta=$ crack activity after overlay;

$\mathrm{a}, \mathrm{b}=$ experimentally determined coefficients.

Using the equivalent stiffness in the crack zone to analyze the reflective cracking, two types of stiffness evolution can be found during the test. The most usual stiffness evolution found in these tests was the logarithmic law (Figure 10) but in some tests an exponential law (Figure 11) was found.

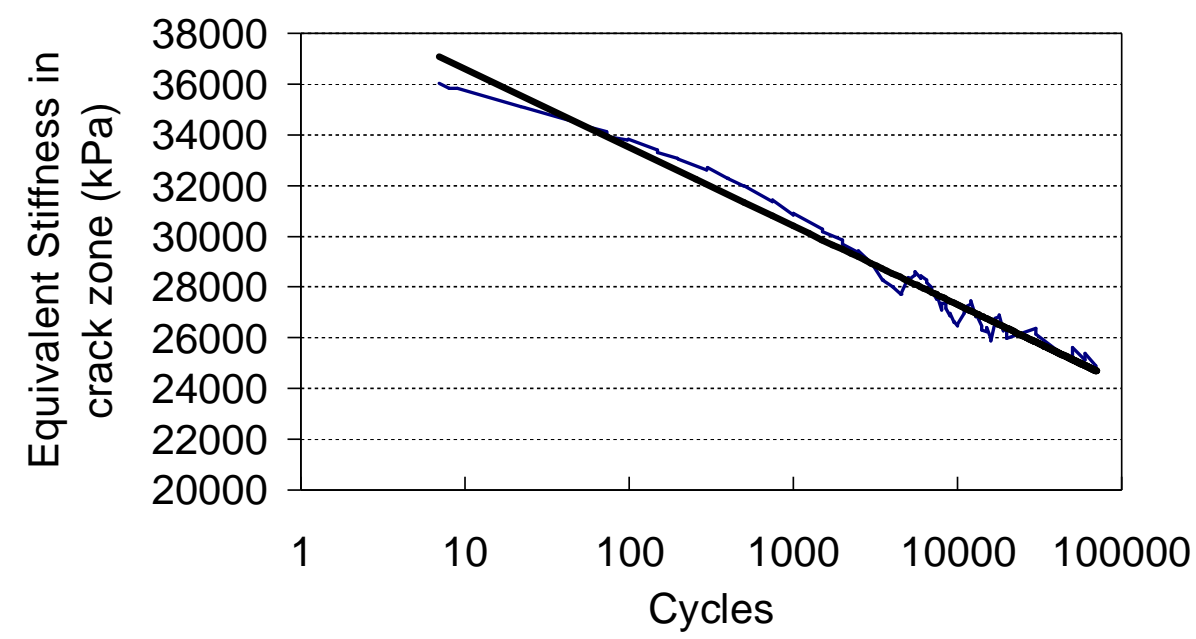

Figure 10. Logarithmic evolution of equivalent stiffness in crack zone 
ROMANIAN JOURNAL

OF TRANSPORT INFRASTRUCTURE

Jorge Pais,

The reflective cracking in flexible pavements

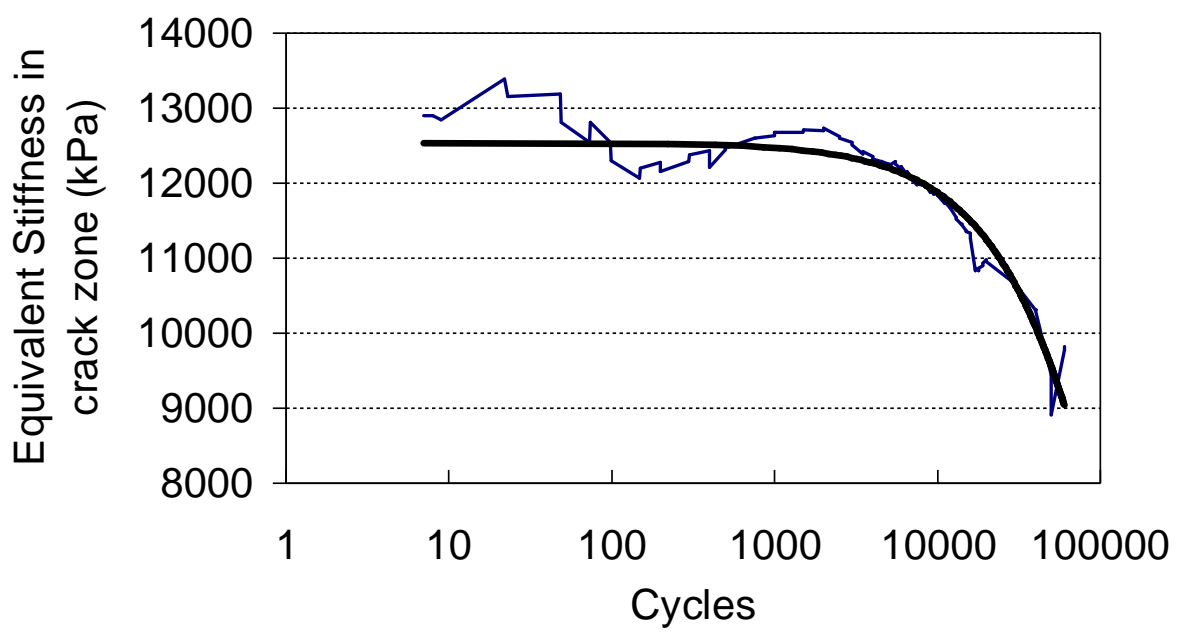

Figure 11. Exponential evolution of equivalent stiffness in crack zone

The reflective cracking fatigue life as function of crack activity and specimen thickness for longitudinal cracks is shown in Figure 12 where one can conclude that the increase of crack activity decreases the fatigue life and the increase of specimen thickness increases the fatigue life. Those two thicknesses and three crack activities can be used to extrapolate the reflective cracking fatigue life for other thicknesses and crack activities. However, further conditions need to be evaluated to demonstrate the validity of these assumptions.

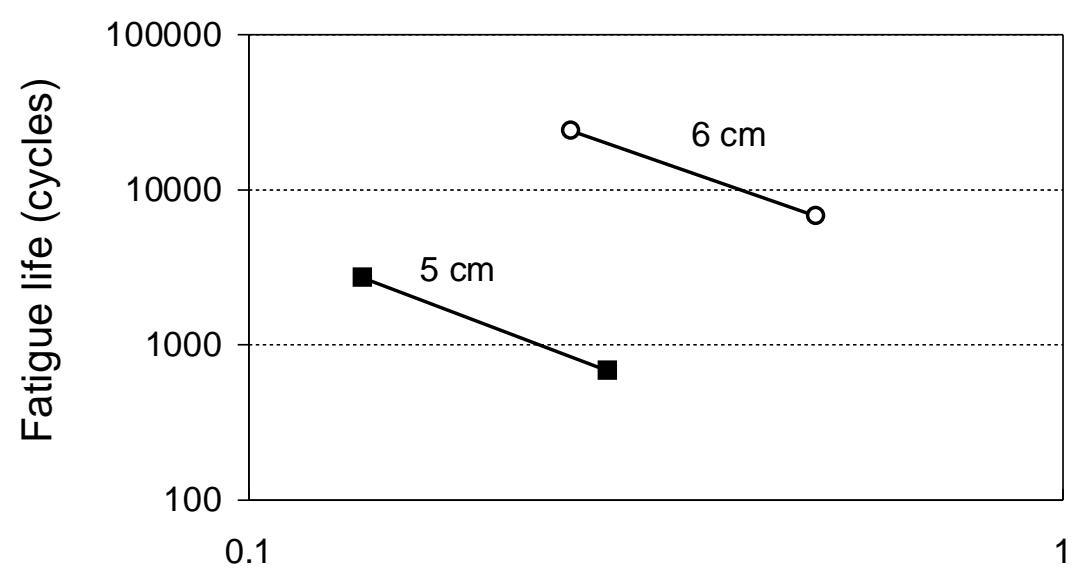

Crack activity $(\mathrm{mm})$

Figure 13. Fatigue life laws for longitudinal cracks 
ROMANIAN JOURNAL

OF TRANSPORT INFRASTRUCTURE

Jorge Pais,

The reflective cracking in flexible pavements

\section{STRAIN LEVEL FOR REFLECTIVE CRACKING}

The reflective cracking fatigue life of an asphalt mixture can also be evaluated applying a strain level to the specimen as in flexural fatigue tests. Thus, a strain level must be calculated for the pavement after overlay as function of the pavement conditions. This concept was introduced by Sousa et al [5] through the Von Mises strain in the overlay above the existing crack. The Von Mises strain was calculated as expressed in Equation 7.

$$
\varepsilon_{V M}=\sqrt{\frac{1}{2}\left(\left(\varepsilon_{1}-\varepsilon_{2}\right)^{2}+\left(\varepsilon_{1}-\varepsilon_{3}\right)^{2}+\left(\varepsilon_{2}-\varepsilon_{3}\right)^{2}\right)}
$$

where ${ }^{\varepsilon_{V M}}=$ Von Mises strain;

$$
\varepsilon_{1}, \varepsilon_{2}, \varepsilon_{3}=\text { Principal strains; }
$$

Using the 3D FEM model presented in Figure 7, the ${ }^{\varepsilon_{V M}}$ as the average Von Mises strain in the elements above the crack was calculated for 384 pavements and fitted in a statistical model as indicated in Equation 8.

$$
\begin{aligned}
& \mathcal{E}_{\mathrm{VM}}\left(1 \times 10^{-6}\right)=a *[\text { Overlay thickness }(m)]^{b} \\
& a=\prod_{i=1}^{6}\left[a_{1 i} * \ln \left(X_{i}\right)+a_{2 i}\right] \\
& b=\prod_{i=1}^{6}\left[b_{1 i} * \ln \left(X_{i}\right)+b_{2 i}\right]
\end{aligned}
$$

where $a_{i j}$ and $b_{i j}=$ coefficients given in Table 3 .

Table 3. Statistical coefficients for the ${ }^{\varepsilon_{V M}}$ model (Equation 8) [R2=0.98]

\begin{tabular}{|c|l|r|r|r|r|}
\hline$i$ & \multicolumn{1}{|c|}{$X_{I}$} & \multicolumn{1}{c|}{$a_{1 i}$} & \multicolumn{1}{c|}{$a_{2 i}$} & \multicolumn{1}{c|}{$b_{1 i}$} & $b_{2 i}$ \\
\hline 1 & $\begin{array}{l}\text { Thickness of the existing cracked } \\
\text { layer }(m)\end{array}$ & $-1.038 \mathrm{E}-04$ & $-1.446 \mathrm{E}-01$ & $7.169 \mathrm{E}-03$ & $1.314 \mathrm{E}-01$ \\
\hline 2 & Thickness of the granular layer (m) & $2.777 \mathrm{E}-01$ & $-4.022 \mathrm{E}+00$ & $9.773 \mathrm{E}-05$ & $-6.368 \mathrm{E}-01$ \\
\hline 3 & Modulus of the overlay layer (MPa) & $-1.173 \mathrm{E}+00$ & $1.212 \mathrm{E}+01$ & $-4.946 \mathrm{E}-01$ & $7.069 \mathrm{E}+00$ \\
\hline 4 & $\begin{array}{l}\text { Modulus of the existing cracked } \\
\text { layer (MPa) }\end{array}$ & $1.281 \mathrm{E}+00$ & $5.070 \mathrm{E}-01$ & $3.923 \mathrm{E}-02$ & $2.641 \mathrm{E}+00$ \\
\hline 5 & $\begin{array}{l}\text { Modulus of the granular layer } \\
\text { (MPa) }\end{array}$ & $-5.160 \mathrm{E}-01$ & $6.964 \mathrm{E}+00$ & $3.265 \mathrm{E}-02$ & $-1.287 \mathrm{E}+00$ \\
\hline 6 & $\begin{array}{l}\text { Modulus of the subgrade layer } \\
\text { (MPa) }\end{array}$ & $-1.775 \mathrm{E}-01$ & $2.385 \mathrm{E}+00$ & $1.875 \mathrm{E}-03$ & $-8.167 \mathrm{E}-01$ \\
\hline
\end{tabular}


ROMANIAN JOURNAL

\section{OF TRANSPORT INFRASTRUCTURE}

The statistical model developed for the Von Mises strain can predict the values calculated using the 3D FEM as can be observed in Figure 14, where the residual (difference between the strain calculated using the FEM and the predicted by the statistical model) is relatively small for all results.

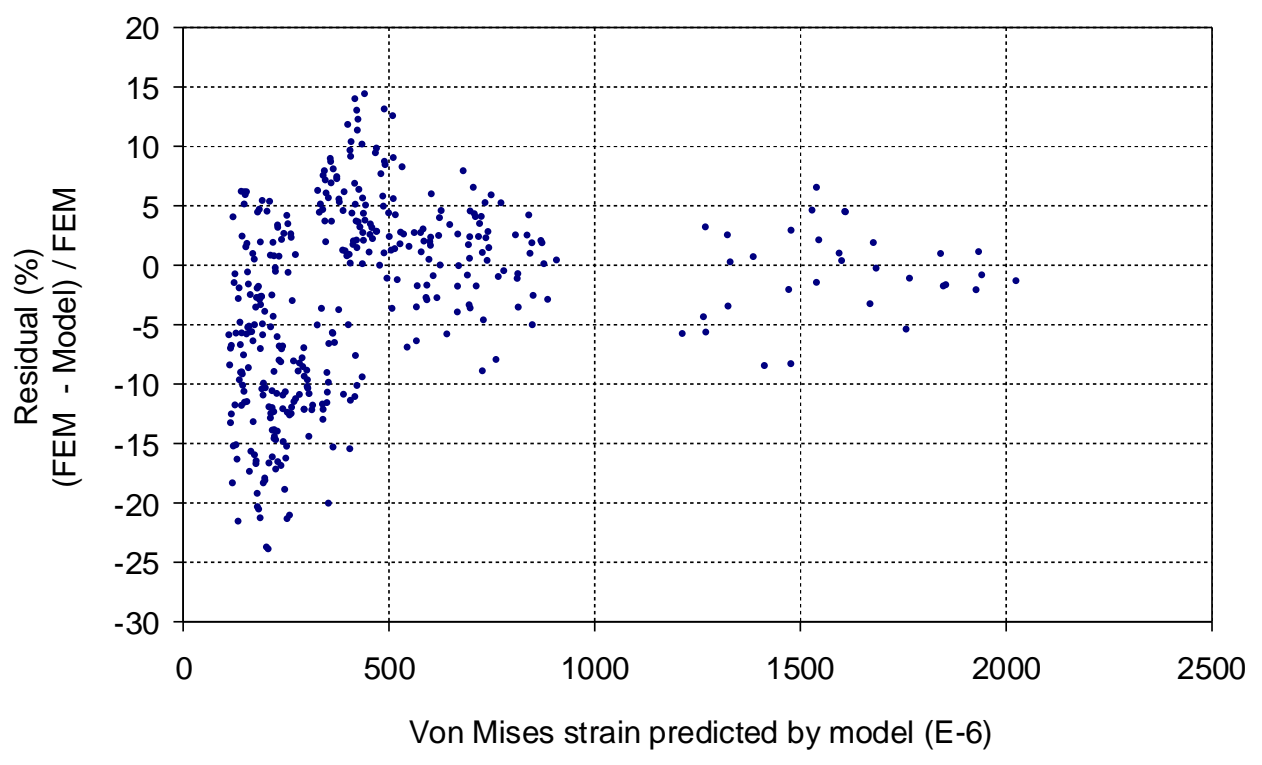

Figure 14. Difference between FEM values and statistical values (residual) for Von Mises strain

The use of the Von Mises strain in the design of pavement overlays can be done by two different approaches. In the first approach, the RCD can be used by applying a vertical displacement to the specimen which corresponds to the Von Mises strain for the overlay thickness to be studied. In the second approach, the Von Mises strain can be applied in a typical flexural fatigue test in which the tensile strain applied to the beam is given by:

$$
\varepsilon_{V M}=\varepsilon_{1}(1+v)
$$

where $\varepsilon_{V M}=$ Von Mises strain;

$\varepsilon_{1}=$ Tensile strain;

$v=$ Poisson ratio. 
ROMANIAN JOURNAL

OF TRANSPORT INFRASTRUCTURE

Jorge Pais,

The reflective cracking in flexible pavements

\section{CONSIDERATION OF TEMPERATURE VARIATION}

Temperature variations have an important influence in the pavement thermal state and thus in the reflective cracking because it increases the horizontal movements in the material above the existing cracks. Depending on the temperature variation, stresses are induced in the overlay in two different ways, which need to be distinguished: through restrained shrinkage of the overlay and through the existing movements of slabs, due to the thermal shrinking phenomenon.

The time variation of pavement thermal state is controlled by: climatic conditions, thermal diffusivity of the materials, thermal conductivity, specific heat, density and the depth below the surface [6].

The temperature distribution in a pavement structure can be obtained through field measurements, using temperature-recording equipment (Datalogger associated with thermocouples) or estimated by using mathematical models. The option of using the field measurement is desirable because actual temperature can be reliably measured and used in stress calculation models. However, this method is relatively slow and only provides information about temperatures in the observed period. On the other hand, a temperature theoretical model may suffer slightly due to lack of accuracies but will give a temperature distribution quickly and cheaply, and can be used to predict temperature distributions under a wide range of conditions, including any unusual or extreme conditions.

In the work carried out by Minhoto et al [7] a 3-D Finite-Element Method was used for modelling the thermal behaviour of pavement. The pavement structures traditionally are idealized as a set of horizontal layers of constant thickness, homogeneous, continuous and infinite in the horizontal direction, resting on a subgrade, semi-infinite in the vertical direction. The thermal configuration of the pavement model was defined in basis of those principles and is presented in Figure 15. This model considers the possibility of thermal data transfer for a mechanical model with the same mesh. 


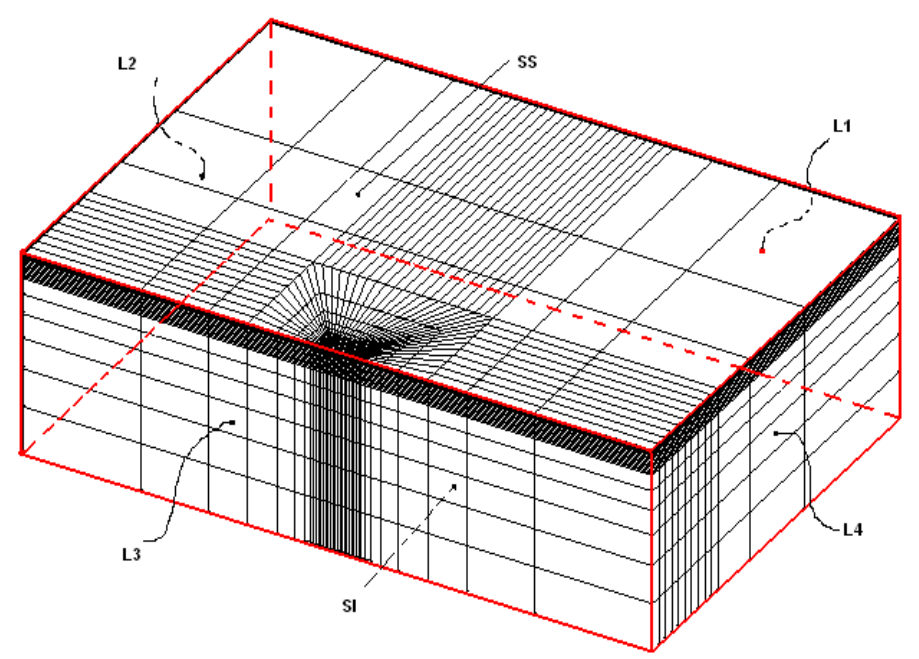

Figure 15. Finite element mesh for thermal model

The adopted mesh was designed also for study of the reflective cracking phenomenon due to the traffic loading and represents an existing pavement, where a crack is simulated through an element with zero-stiffness, and a layer on top of the existing pavement representing an overlay. This mesh was described in other works by Minhoto et al [8] and [9].

The finite element model used in numerical thermal analysis was performed using a general finite elements analysis source code, ANSYS 7.0. This analysis is a 3-D transient analysis, using a standard finite element discretization, in space. In the design of the thermal finite-element mesh, the compatibility of mesh with other mechanical models was observed.

The designed mesh has 13538 elements. For three-dimensional thermal analysis, 3-D solid element, SOLID70, was used. This element, applicable to a three-dimensional transient thermal analysis, has capability for threedimensional thermal conduction, according with previous explanation. The element has eight nodes with a single degree of freedom, defined as temperature, at each node.

The thermal properties of pavement material, such as thermal conductivity, specific heat and density, for each pavement layer, were defined in the "material properties" of this element, when the model was developed.

The main goal of this study is to show the good accuracy temperature prediction that can be obtained with the model when compared to the field pavement thermal condition.

Firstly, a FEM numerical analysis for the temperature distribution in a pavement of a trial section was performed for the weather conditions (air temperature, solar radiation and wind speed) during one year [7]. The model 
ROMANIAN JOURNAL

\section{OF TRANSPORT INFRASTRUCTURE}

Jorge Pais,

The reflective cracking in flexible pavements

validation was made by statistical analysis between the FEM numerical temperature results and the field-measured temperatures and presented in Minhoto et al. [7].

During a year (January 2004 to December 2004), pavement temperatures were measured at a newly pavement section using seven thermocouples installed in the pavement, at seven different depths: at surface, $27.5 \mathrm{~mm}, 55 \mathrm{~mm}, 125$ $\mathrm{mm}, 165 \mathrm{~mm}, 220 \mathrm{~mm}$ and $340 \mathrm{~mm}$. The top one was installed just at the pavement surface. The depths for the other six were chosen to give a good representation of the whole asphalt layers. Pavement temperatures were recorded every hour, every day during the year.

Figures 16 present a comparison between the FEM calculated temperature and the in pavement measured temperature is made that allows to conclude that the temperature model used to predict the pavement temperature presents a good accuracy in the prediction of the temperature in the first layers of the pavement where the differences between calculated and observed temperatures are too small.

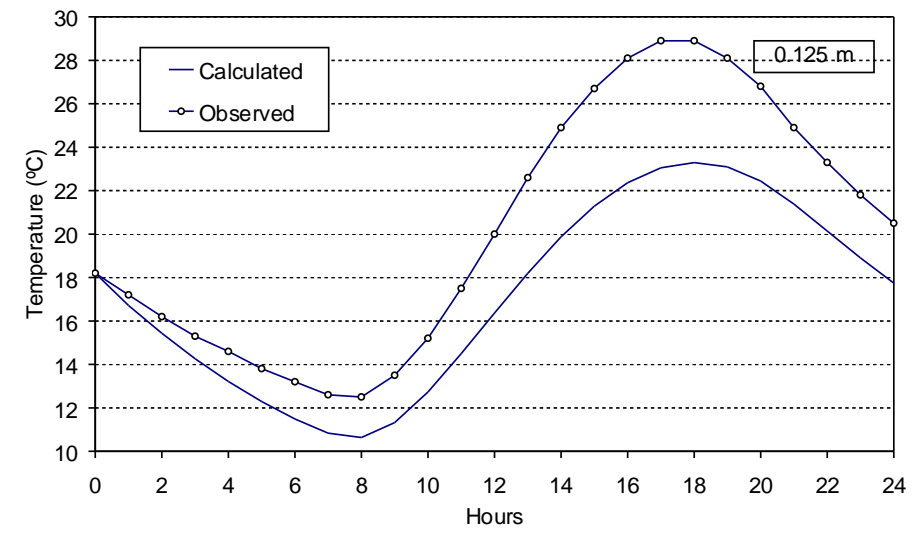

Figure 16. Comparison between calculated and observed temperature

However, the pavement temperature presents variation during the days as it can be observed in Figure 17, respectively for the pavement surface and at a deep of $0.125 \mathrm{~m}$ of a pavement with $30 \mathrm{~cm}$ asphalt layers. 
ROMANIAN JOURNAL

OF TRANSPORT INFRASTRUCTURE

Jorge Pais,

The reflective cracking in flexible pavements

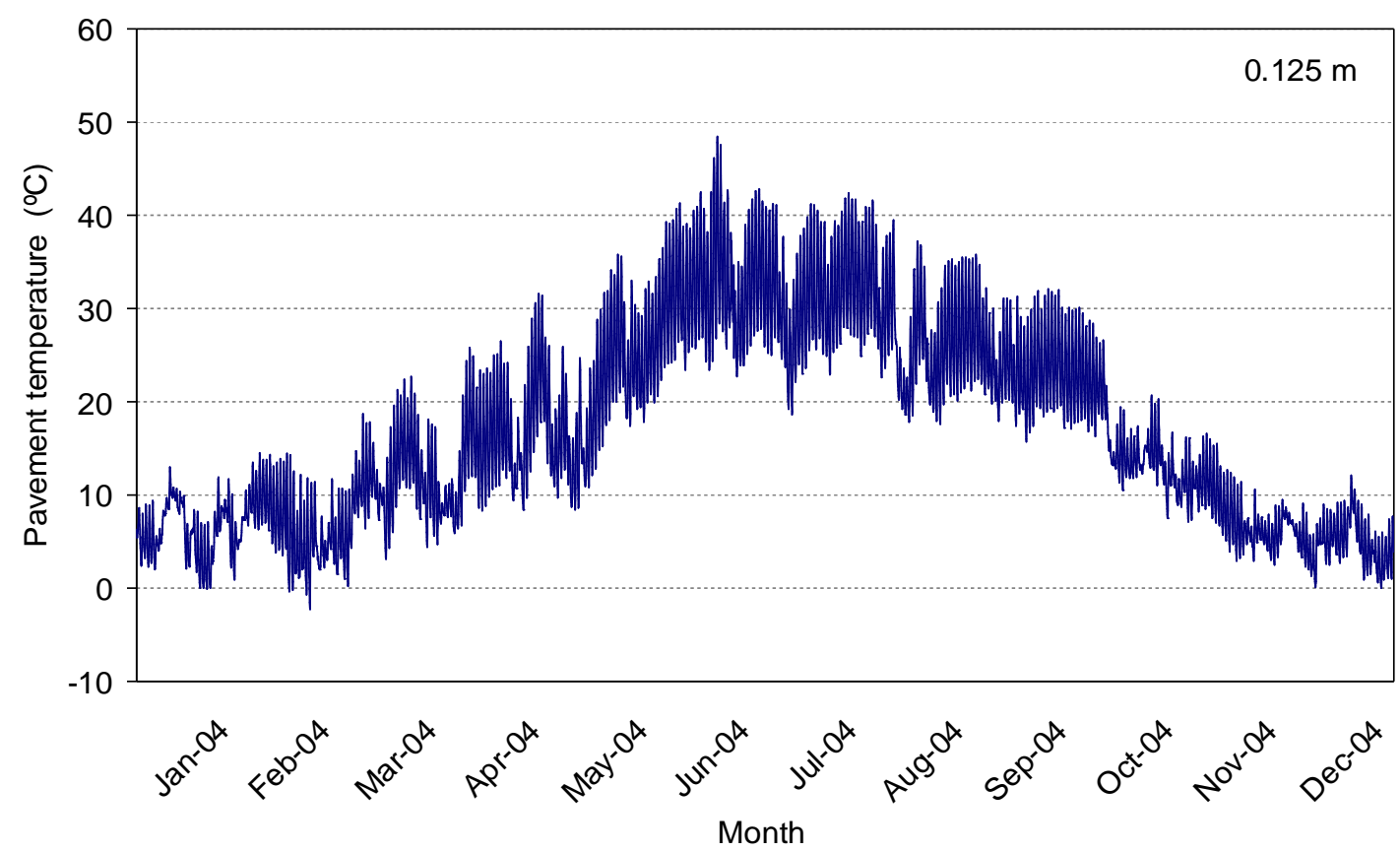

Figure 17. Observed temperatures at $0.125 \mathrm{~m}$ during one year

The reflective cracking analysis to consider the temperature variation during the day and during the year must be carried out as represented in the flowchart represented in Figure 18.

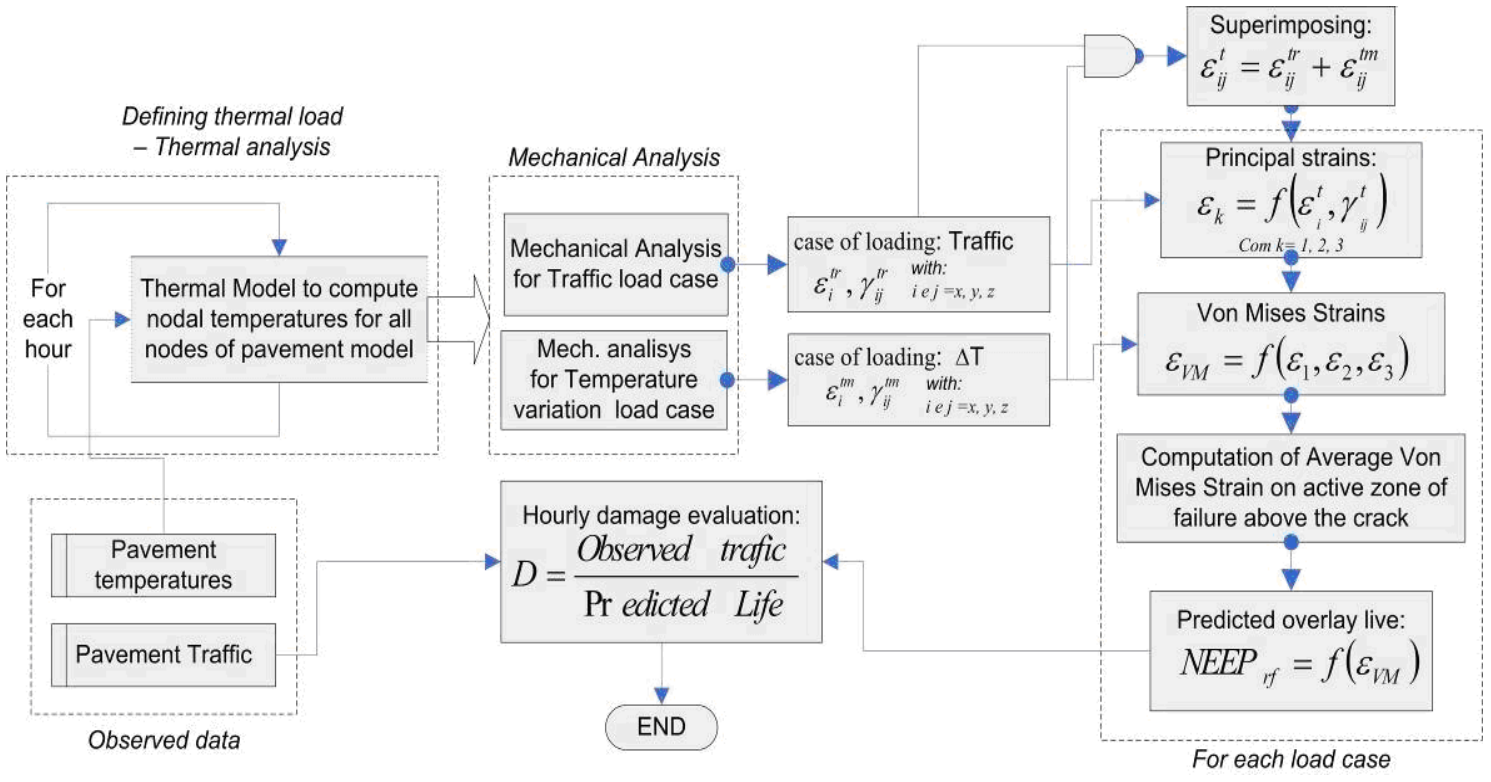

Figure 18. Procedures to consider the temperature variation in the reflective cracking 
ROMANIAN JOURNAL

\section{OF TRANSPORT INFRASTRUCTURE}

In one-year time-period the main results obtained from this simulation were: i) the Von Mises strains; ii) predicted overlay life; iii) overlay damage. These calculations were performed for traffic loading, temperature variations and the combination of both, traffic and temperature. In Figure 18, the hourly means Von Mises strain evolution along the year is plotted against the time.

The Von Mises strain for each loading case was used to predict the pavement life after overlying. Figure 20 shows the hourly predictive overlay life resulting from traffic and traffic $+\Delta \mathrm{T}$ loading cases.

The results show that the overlay life obtained from traffic loading is higher than the overlay life obtained from traffic $+\Delta \mathrm{T}$ loading, mainly in winter season, when low temperatures occur. In summer, the predicted overlay life is inferior to that of winter. Thus, the effect of traffic $+\Delta \mathrm{T}$ may have a significant influence on the overlay life, which will justify a special attention.

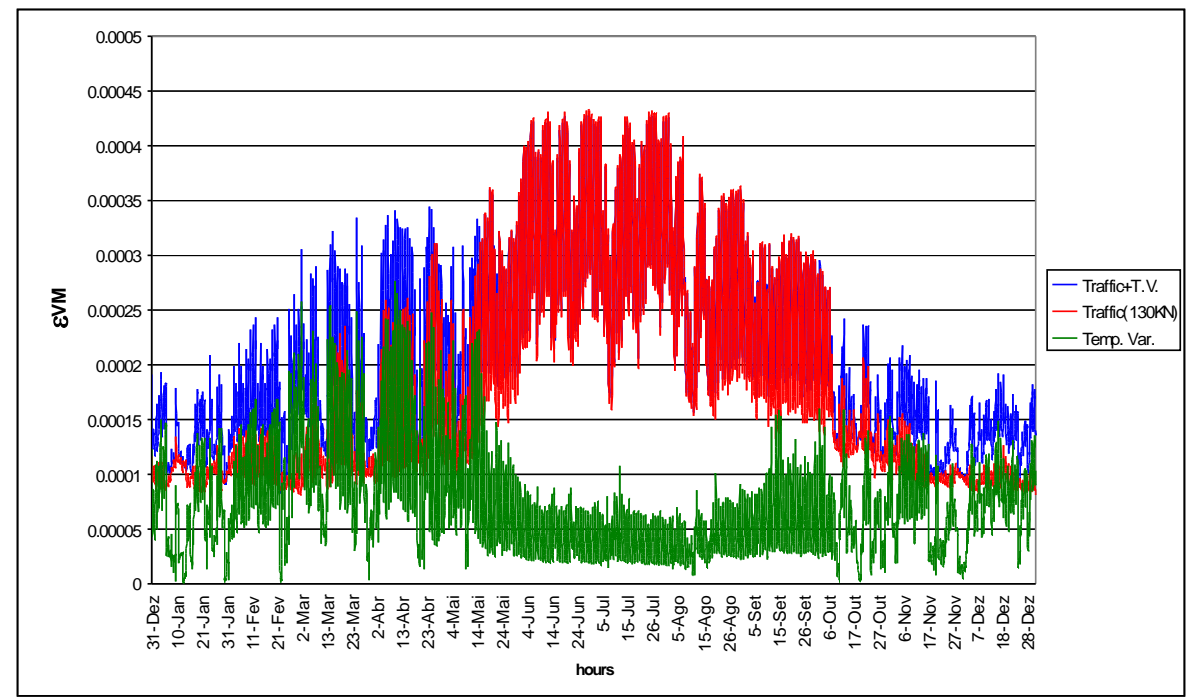

Figure 19. Von Mises strain for all loading cases 
ROMANIAN JOURNAL

\section{OF TRANSPORT INFRASTRUCTURE}

Jorge Pais,

The reflective cracking in flexible pavements

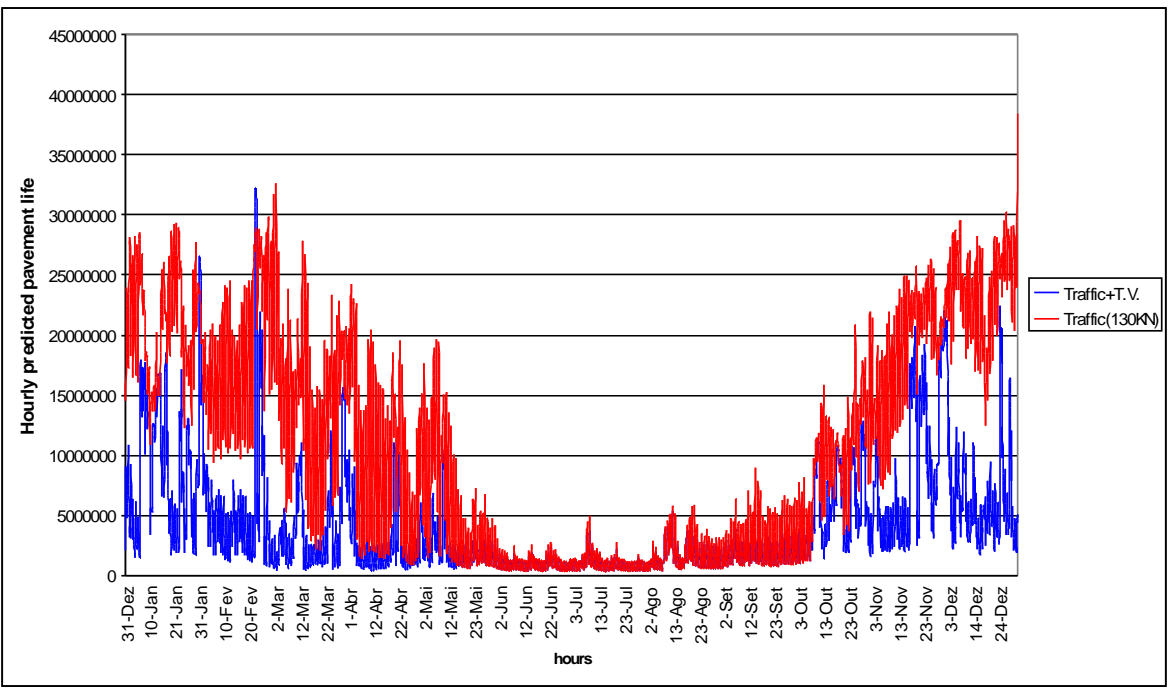

Figure 20. Predicted overlay life for traffic+temperature variations

\section{MULTI-CRACKS MODELING}

Cracks in the pavements tend to reflect through an overlay placed on the cracked pavement due to the traffic and temperature effects, depending on the magnitude of the stress concentrations at the tip of the crack, the resistance of the overlay material to crack propagation and the characteristics of the interface between the overlay and the existing pavement. The stress concentration at the crack tip results of the bending, shearing and tearing actions of traffic loads and tensile and bending actions caused by temperature and moisture movements as well as temperature and moisture gradients [10].

To assess the cracking in pavement overlays, many investigations have been conducted in terms of experimental and numerical modeling. The first studies started by Majidzadeh et al [11] with the application of the fracture mechanics in the analysis of pavement fatigue where the fatigue life of paving mixtures in terms of material constants, geometry, boundary conditions, and the state of stress is predicted. In that work, fatigue is defined in terms of crack initiation, influence on crack growth, and critical stress intensity at the critical failure point. The laboratory tests to support that study utilized notched and unnotched beams supported in an elastic foundation to predict the fracture parameters. The determination of the fracture parameters (i.e the stress intensity factors) were made based on experimental assumptions from fracture tests.

Later on, Van Gurp and Molenaar [12] developed a procedure to predict the reflective cracking in asphalt overlays using linear elastic finite element models, by analyzing the crack propagation form the old cracked asphalt layers 
ROMANIAN JOURNAL

\section{OF TRANSPORT INFRASTRUCTURE}

Jorge Pais,

The reflective cracking in flexible pavements

through the new overlay. The models used only considered the traffic influence simulating mode I and II of crack opening by applying the load above the crack and adjacent to the crack.

Since then, the numerical modeling has been used in the assessment of reflective cracking by different methods. Paulino et al [13] applied a cohesive zone fracture model to simulate crack initiation and propagation in asphalt concrete using intrinsic constitutive laws to connect traditional finite elements to simulate localized damage and softening behavior. Nesnas and Nunn [14] used a finite element model with multi-cracks to investigate the top-down cracking in cement treated base pavements.

More recently, $\mathrm{Wu}$ and Harvey [15] developed a finite element model to evaluate the performance of several asphalt mixes that contain binders with recycled rubber. The mechanistic model was based on non-local continuum damage mechanics and the finite element method and the damage evolution law parameters were identified using laboratory fatigue test data. The finite element model was the first model used in the reflective cracking analysis that was created with multiple cracks, simulating the alligator cracking in the existing pavements before the placement of a pavement overlay.

However, these studies did not investigate the influence of the existence of multiple cracks or the influence of the spacing between cracks in the evaluation of the reflective cracking. This subject takes a significant importance because cracked pavements, mainly the flexible pavements, usually present multiple cracks (alligator cracks) before the pavement overlaying.

Thus, this paper aims to study the influence of the existence of multiple cracks in finite element models on reflective cracking. This influence is assessed by the state of stress and strain in the pavement overlay, just above the existing cracks in the old pavement.

This effort consisted of developing a 2D finite element model which was created, using the plain strain mode, in which 10 cracks were modeled in the cracked layer and spaced $10 \mathrm{~cm}$ from each other. The model has the ability to easily change the crack spacing, the elimination of some cracks to create any configuration of cracking with any cracking spacing, from a pavement with only one crack to a pavement up to 10 cracks.

The application of this model resulted in creating different cracking configurations to study the influence of crack spacing on the reflective cracking phenomenon. The study investigated three different overlay configurations: 10, 20 and $30 \mathrm{~cm}$ overlay thicknesses over an existing cracked pavement.

Pais et al [16] developed a 2D finite elements model to study the presence of multi-cracks in the reflective cracking behavior. The model has a pavement 
ROMANIAN JOURNAL

\section{OF TRANSPORT INFRASTRUCTURE}

configuration consisting of an overlay layer, an existing asphalt cracked layer, a granular base layer and a subgrade layer, as schematically represented in Figure 21.

The model considers the existence of full friction as interface between old and new pavement layers. The existing asphalt layer was modeled with 10 cracks, numbered from 1 to 10 , starting from the left side of the model. The distance between cracks was set to $10 \mathrm{~cm}$ and the crack width was set to $3 \mathrm{~mm}$. The model has the ability to easily allow the elimination of some cracks to create any configuration of cracking with any cracking spacing, from a pavement with only one crack to a pavement up to 10 cracks.

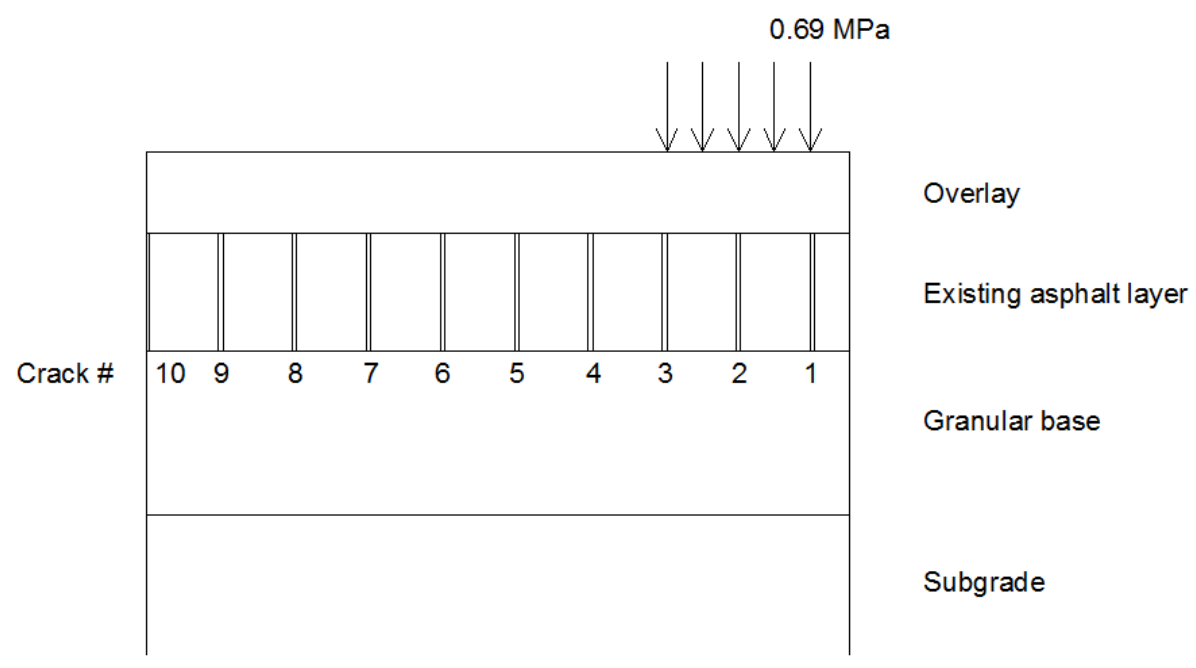

Figure 21. Schematic representation of the finite elements model

One of the objectives of this work was to evaluate the difference between modeling of multiples cracks as compared to a single crack. This can be observed by the representation of the Von Mises strain presented in Figure 22 and 23, respectively for a pavement with only one crack modeled and the pavement with $10 \mathrm{~cm}$ spaced cracks. The analysis of these figures shows the difference between the state of strain in the overlay associated with the presence of either a single or multiple cracks. The difference is also visible in the state of strain above the existing cracks which is responsible for the reflective cracking. 
ROMANIAN JOURNAL

OF TRANSPORT INFRASTRUCTURE

Jorge Pais,

The reflective cracking in flexible pavements

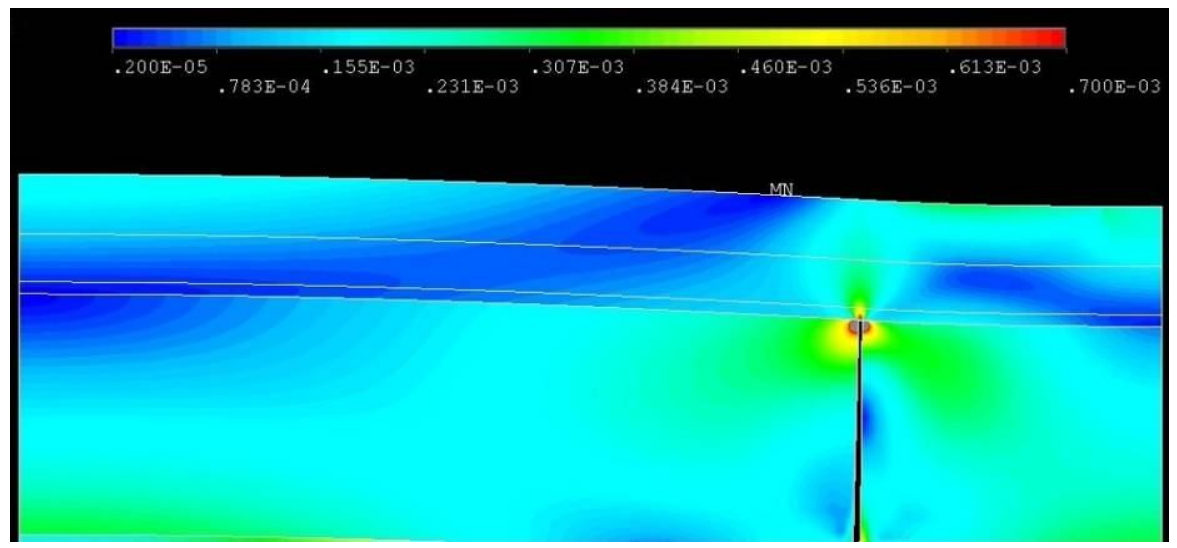

Figure 22. Von Mises strain in a pavement with a single crack (\#3)

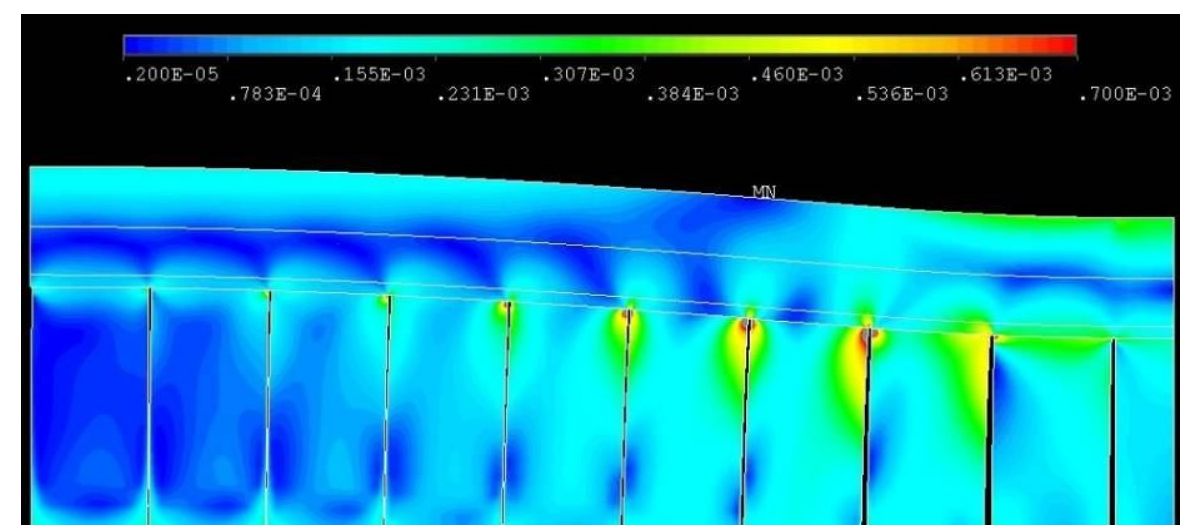

Figure 23. Von Mises strain in a pavement with multiple cracks

The first analysis of this study of carried out for the cases of single cracks. For these cases, the strain level in the pavement with $10 \mathrm{~cm}$ thickness overlay is indicated in Figure 24, where Ex represents the horizontal strain, Ey represents the vertical strain, Exy represents the shear strain and the Evm represents the Von Mises shear strain. The analysis of single crack modeling indicates that the vertical strain is almost constant when cracks below the load (1,2 and 3) are modeled. Also, for the other cracks, the vertical strain is constant. In terms of horizontal, shear and Von Mises strain, they increase as the cracks moves away from the load but after crack 4 the strain level reduces significantly, except for the horizontal strain. This analysis shows that when only one crack is modeled, that should be the crack 4, which is $10 \mathrm{~cm}$ away from the load. Usually, the modeling of a single crack simulating the mode II of crack opening is simulated by crack 3, which is around $20 \%$ less them the strain level above crack 4 . 
ROMANIAN JOURNAL

OF TRANSPORT INFRASTRUCTURE

Jorge Pais,

The reflective cracking in flexible pavements

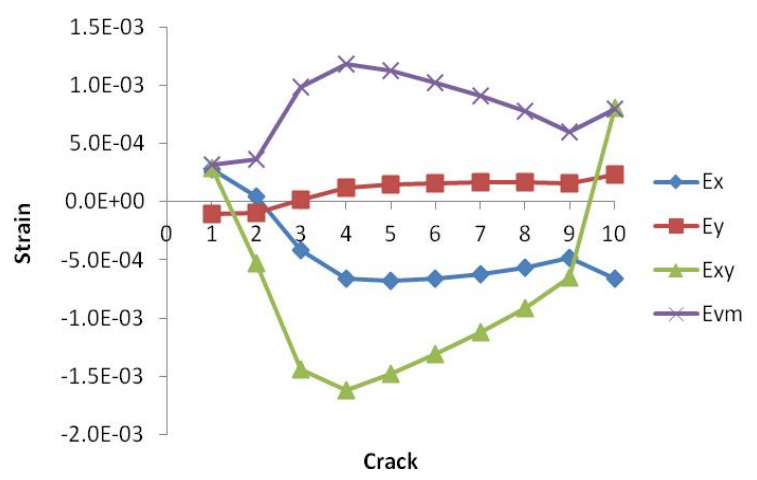

Figure 24. Strain in the overlay for models with only one crack

For pavements with 20 and $30 \mathrm{~cm}$ overlay thickness, the conclusion is identical, ie, the maximum state of strain appears not for the crack adjacent to the load but away from the load, as it can be observed in Figure 25 where the Von Mises strain is represented as function of the overlay thickness and crack number. As the overlay thickness increases, the Von Mises strain decreases and the maximum strain appears for crack 6 , ie, $30 \mathrm{~cm}$ away from the load.

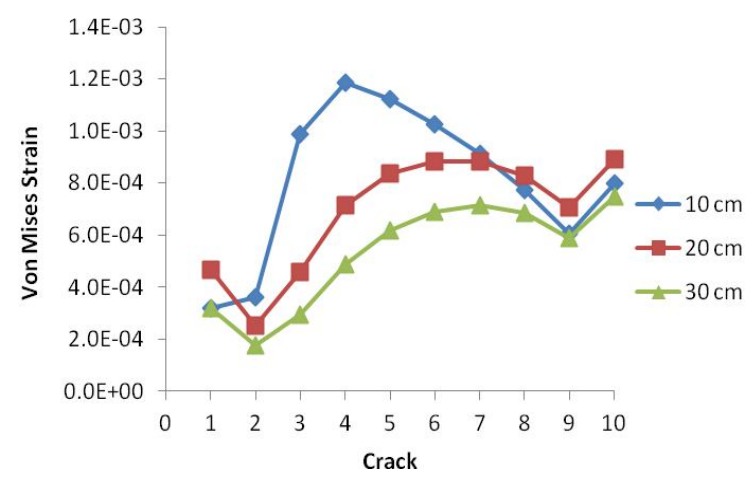

Figure 25. Influence of overlay thickness of Von Mises strain for single crack

The analysis of $10 \mathrm{~cm}$ spaced cracks (Figure 26) shows that, for this crack spacing, the consideration of multiple cracks is unfavorable, i.e, produces von Mises strains lesser that the one obtained when only one crack is modeled. 


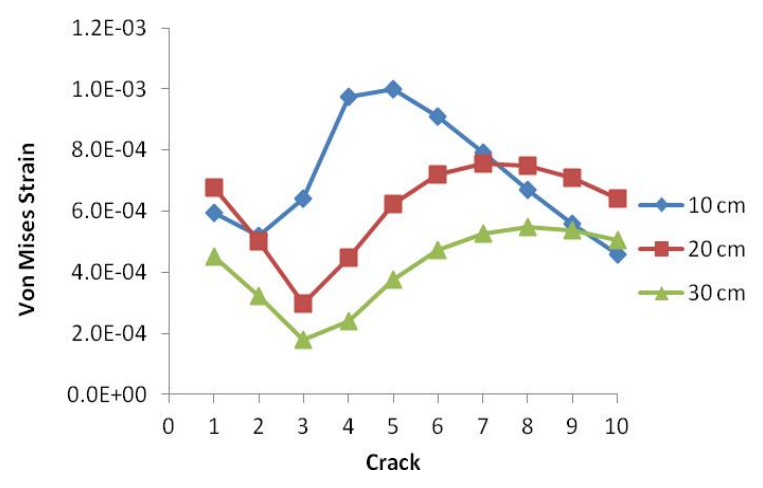

Figure 26. Influence of overlay thickness of Von Mises strain for $10 \mathrm{~cm}$ crack spacing

Different conclusions can be obtained from the results for $50 \mathrm{~cm}$ spaced cracks where a Von Mises strain level greater or identical to the one obtained for single cracks (mainly for crack \#4) was achieved (Figure 27). This appears mainly when a $50 \mathrm{~cm}$ crack spacing exists and there is a crack below the load and the other crack is away from the load. If the first crack is not below the load, then the strain level in that crack and in the other cracks is reduced compared to the maximum observed for a single crack \#4. However, the maximum value observed for these cases is almost identical to the one observed for a single crack \#4 and thus it is enough to consider the existence of only one crack, not adjacent to the load but some centimeters away from the load, depending of the overlay thickness.

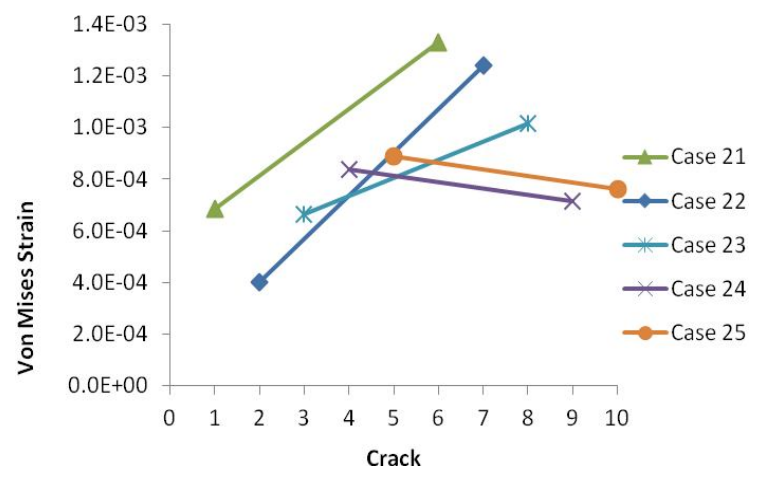

Figure 27. Von Mises strain in the overlay for $50 \mathrm{~cm}$ crack spacing

\section{CONCLUSIONS}

To evaluate the reflective cracking potential, the crack activity must be measured. This crack activity before overlay can be used to estimate the crack activity after overlay. Both crack activities can be well correlated with old pavement and overlay characteristics. 
ROMANIAN JOURNAL

\section{OF TRANSPORT INFRASTRUCTURE}

Jorge Pais,

The reflective cracking in flexible pavements

After overlay, crack activity is influenced by the overlay properties, namely the overlay thickness and material stiffness.

The laboratory study with the reflective cracking device showed that the stiffness behavior during test follows either an exponential law or a logarithmic law.

The reflective cracking fatigue life is influenced mainly by the crack activity after overlay and overlay thickness. The increase of crack activity decreases the fatigue life and the increase of specimen thickness, representing the overlay thickness, increase the fatigue life.

This approach appears to open promising avenues and further research should be made in this area.

The temperature variations in bituminous layers (overlay and cracked layers) which cause a state of tension in the overlay, is particularly important for estimate the overlay life. The effect of accumulation of thermal stresses due the effect of temperature variations and traffic loading will reduce the overlay life.

The presence of multiple cracks can lead to a state of stress/strain higher than those obtained with only one crack. Also the position of the crack modeled in the finite elements analysis have a significant influence in the state of stress/strain obtained. However, the consideration of only one crack is sufficient to obtain significant results in the reflective cracking modeling.

\section{REFERENCES}

[1] R. HAAS, P. JOSEPH, "Design oriented evaluation of alternatives for reflection cracking through pavement overlays" First International Conference on Reflective Cracking in Pavements, Liege, Belgium, 1989.

[2] A. HALIM, W. PHANG, R. HAAS, "Realizing structural design objectives through minimization of construction induced cracking" Sixth International Conference on Structural Design of Asphalt Pavements, Michigan, 1987.

[3] J. PAIS, "The reflective cracking in flexible pavement overlay design (in Portuguese)", Ph. D. Thesis, University of Minho, Portugal, 1999.

[4] J. SOUSA, S. SHATNAWI, J. COX, "An approach for investigating reflective fatigue cracking in asphalt-aggregate overlays", Proceeding of the Third International RILEM Conference. 1996.

[5] J. SOUSA, J. PAIS, G. WAY, "A mechanistic-empirical based overlay design method for reflective cracking", Asphalt Rubber 2003 Conference, Brasilia, Brasil, 2003. 
ROMANIAN JOURNAL

\section{OF TRANSPORT INFRASTRUCTURE}

Jorge Pais,

The reflective cracking in flexible pavements

[6] J. SOUSA, J. PAIS, R. SAIM, G. WAY, R. STUBSTAD, "Development of a mechanistic-empirical based overlay design method for reflective cracking", Transportation Research Board, Washington, 2002.

[7] M. MINHOTO, J. PAIS, P. PEREIRA, L. PICADO-SANTOS, "Predicting asphalt pavement temperature with a three-dimensional finite element method", Journal of the Transportation Research Board, $\mathrm{n}^{\circ}$ 1919, 2005.

[8] M. MINHOTO, J. PAIS, P. PEREIRA, "Influence of temperature variation on the reflective cracking behaviour of asphalt overlays", Asphalt Rubber 2006 Conference, Palm Springs, USA, 2006.

[9] M. MINHOTO, J. PAIS, P. PEREIRA, L. PICADO-SANTOS, "Low-temperature influence in the predicted of pavement overlay life", Asphalt Rubber 2003 Conference, Brasilia, Brasil, 2003.

[10] A. MOLENAAR, J. POTTER, "In Prevention of Reflective Cracking in Pavements". Edited by Vanelstraete, A. and Francken, L. RILEM Report 18. Published by E \& FN Spon, 2-6 Boundary Row, London SE1 8HN. ISBN 041922950 7, 1997.

[11] K. MAJIDZADEH, E. KAUFFMANN, D. RAMSAMOOJ, "Application of fracture mechanics in the analysis of pavement fatigue". Proceeding of the Association of Asphalt Paving Technologists, vol 40, pp 227-246, 1971.

[12] C. VAN GURP, A. MOLENAAR, "Simplified method to predict reflective cracking in asphalt overlays". Proceeding of the Reflective cracking in pavements Assessment and control conference, Liege, 1989.

[13] G. PAULINO, S. SONG, W. BUTTLAR, "Cohesive zone modeling of fracture in asphalt concrete". Proceeding of the Cracking in pavements - Mitigation, risk assessment and prevention conference, Limoges, 2004.

[14] K. NESNAS, M. NUNN, "A model for top-down reflection cracking in composite pavements". Proceeding of the Cracking in pavements - Mitigation, risk assessment and prevention conference, Limoges, 2004.

[15] R. WU, J. HARVEY, "Evaluation of reflective cracking performance of asphalt mixes with asphalt rubber binder using HVS tests and non-local continuum damage mechanics". Pavement Cracking - Al-Qadi, Scarpas \& Loizos (eds), Taylor \& Francis Group, London, ISBN 978-0-415-47575-4, 2008.

[16] J. PAIS, M. MINHOTO, S. SHATNAWI, "Multi-cracks modeling in reflective cracking", 7th International Rilem Conference on Cracking in Pavements, Delft, The Netherlands, 20-22 June, 2012. 